\title{
Pattern of Ocular Disorders in A Semi-Urban Community in Rivers State, Nigeria. --Implications for Eye Care Planning and Budgeting
}

\section{Ireju Onyinye Chukwuka* and Elizabeth Akon Awoyesuku}

Department of Ophthalmology, College of Health Sciences, University of Port Harcourt, Nigeria

*Corresponding Author: Ireju Onyinye Chukwuka, Department of Ophthalmology, College of Health Sciences, University of Port Harcourt, Nigeria.

DOI: 10.31080/ASOP.2020.03.0101
Received: February 16, 2020

Published: February 27, 2020

(C) All rights are reserved by Ireju Onyinye Chukwuka and Elizabeth Akon Awoyesuku.

\begin{abstract}
Aim: This preliminary (pilot) study was to elucidate the demographic characteristics and pattern of Ophthalmic Disorders at a Community Eye Outreach in a Semi-Urban Area of Rivers State, Nigeria and its implications for eye care planning and budgeting.

Methodology: A descriptive cross-sectional study was done. Participants at a one-day free eye camp at Rumuapu community had a comprehensive ophthalmic examination involving visual acuity, ocular examination of the anterior and posterior segment, tonometry and refraction. The data generated was subsequently analyzed using SPSS version 20.

Results: 104 subjects were seen with a mean age of $38.3 \pm 16.6$ years. $71.2 \%$ of the participants were female while $28.8 \%$ were male. $30.8 \%$ were in the 41 - 50years age group, $80 \%$ of the participants had normal distant vision but $77.9 \%$ were presbyopic. The most common cause of ocular morbidity was refractive error closely followed by allergic conjunctivitis.

Conclusion: The commonest Ophthalmic disorder in our study was refractive error which occurred with a mean age of 36.2 years, followed by allergic conjunctivitis. More females than males attended the free eye screening activities and the prevalence of visual impairment was $22 \%$.
\end{abstract}

Keywords: Ocular Disorders; Semi-Urban; Eye Care; Planning and Budgeting

\section{Introduction}

Free eye screening programs have a significant impact in developing economies as they present an avenue for economically disadvantaged individuals to have access to ophthalmic care. They also help in mopping up cataract and informing beneficiaries about other causes of preventable blindness [1].

The Nigerian National Blindness and Visual impairment Survey puts the overall prevalence of blindness in Nigeria at $4.2 \%$ and $3.4 \%$ in South -South Nigeria [2].

Knowledge of ocular diseases prevalent in different regions has implications for preventive ophthalmology as scarce resources can be better channeled to prevalent disease with improvement in ophthalmic health. The aim of this study is to elucidate the ophthalmic disorders prevalent in a semi-urban community as well as demonstrate its association with the age of the participants. Rumuapu is a semi urban community in Obio Akpor local government area in Rivers State and has no health care or eye care facility domiciled in it. Residents have to travel over one hour to the nearest eye care facility in the State. This pilot study aims to elucidate the pattern of ocular disorders prevalent in this community, as well as its association with age to enable appropriate healthcare planning and budgeting of available resources. To the best of our knowledge no data exists from this community. 


\section{Methodology}

A descriptive cross-sectional study was employed. Participants were seen at a one-day free eye camp conducted at Rumuapu community in Obio/Akpor local government area, Rivers State on $18^{\text {th }}$ November, 2017. All participants gave a verbal and written /signed informed consent to partake in the study while parents gave signed informed consent for underage children. The study was carried out in accordance with the tenets of Helsinki declaration and every participant was free to withdraw from the research at any time. Minor ocular disorders were treated on site while those requiring more investigations were referred to the nearby tertiary care facility. Ethical approval was obtained from the ethical review board of our institution. All participants had a comprehensive ophthalmic examination. This included visual acuity using a Snellen chart for distant acuity and the near vision using the near chart. The anterior segment was visualized using a pen torch while the posterior segment was seen using the Welch Allyn direct Ophthalmoscope. Participants who were unable to read the $6 / 6$ on the Snellen chart were given a pin hole and visual acuity repeated. Those with improvement in visual acuity had their refraction done using Welch Allyn retinoscopes. Tonometry was also done on all participants using a non-contact Keeler tonometer. There were no inclusion and exclusion criteria as we wanted the data to be truely representive of the ocular health status of the residents of Rumuapu community.

Data on age, sex, visual acuity and ophthalmic disorders of the participants were entered into Microsoft Excel and exported to IBM Statistical Package for Social Sciences (SPSS) version 20 for descriptive and inferential statistical analyses. Descriptive statistics included frequencies and percentages for categorical variables while means and standard deviation were employed for numerical variables. The differences in mean ages across type of ophthalmological disorders were compared using one-way Analysis of Variance (ANOVA) statistics. Significant level was set at $\mathrm{p}<0.05$.

\section{Results}

104 subjects were seen with a mean age of $38.3 \pm 16.6$ years. $71.2 \%$ of the participants were female while $28.8 \%$ were male (M:F $=1: 2.4$ ) and $30.8 \%$ were in the $41-50$ years age group. More than $80 \%$ of the participants had visual acuity better than $6 / 18$ in both eyes. Refractive error was the commonest condition encountered (77.9\%) followed by allergic conjunctivitis (17.3\%) and glaucoma suspects (10.6\%). Most of the participants with refractive error had presbyopia. The mean age of those with refractive error was
36.2 years while the mean age of cataract was 70.0 years. Cataract was uncommon $(2.9 \%)$.

The age group with the largest number of attendees was the 4150 years age group (Figure 1), followed by the 31 - 40 years and the 11 - 20 years age group. The lowest attendance (2.9\%) was by the over 70 years old age group.

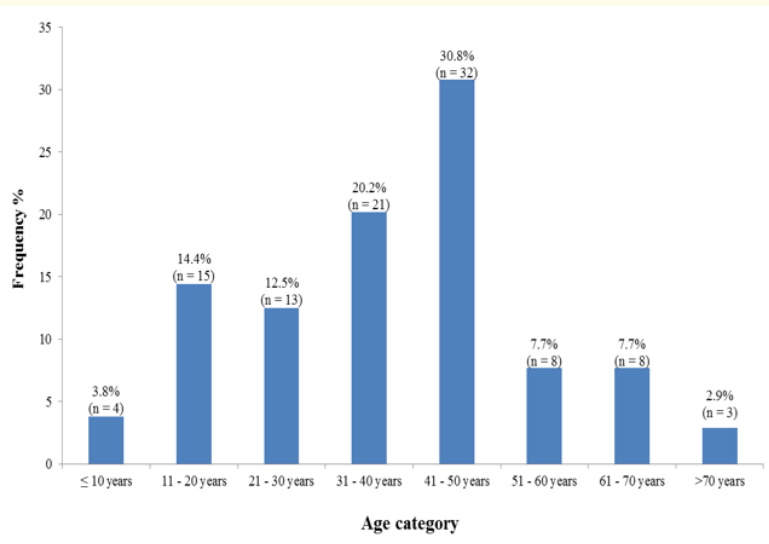

Figure 1: Age distribution of participants in the study $(\mathrm{N}=104)$.

\section{Sex distribution}

The vast majority of attendees were female (71.2\%) while the males were only $28.8 \%$.

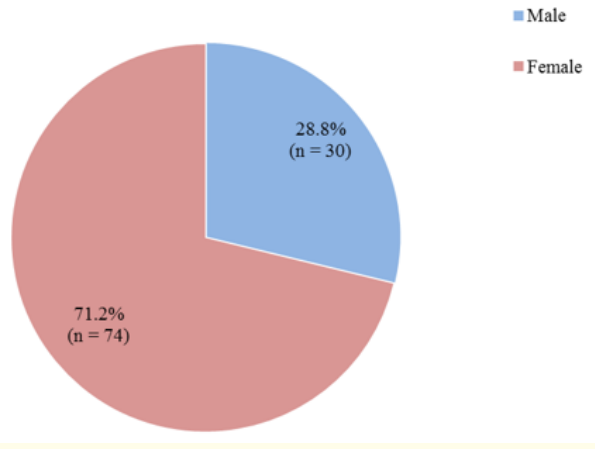

Figure 2: Sex distribution of participants in the study $(\mathrm{N}=104)$.

\section{Visual acuity findings}

About $79 \%$ of participants had a visual acuity better than $6 / 18$ in their right and left eyes. 


\begin{tabular}{|l|c|c|}
\hline Visual acuity & $\begin{array}{c}\text { Right Eye Frequency } \\
\text { (Percentage) }\end{array}$ & $\begin{array}{c}\text { Left Eye Frequency } \\
\text { (Percentage) }\end{array}$ \\
\hline Better than $6 / 18$ & $83(79.8)$ & $82(78.8)$ \\
\hline $6 / 18-6 / 36$ & $15(14.4)$ & $13(12.5)$ \\
\hline Worse than $6 / 36$ & $6(5.8)$ & $9(8.7)$ \\
\hline Total & $104(100.0)$ & $104(100.0)$ \\
\hline
\end{tabular}

Table 1: Visual acuity findings of right and left eyes of participants.

Ophthalmic disorders

The most frequent ophthalmic finding was refractive error, followed by allergic conjunctivitis and glaucoma suspects while the least common were ocular albinism, and dry eye disorder. $3.8 \%$ of participants had no ophthalmic disorder.

Comparison of mean ages of participants based on ophthalmological disorders

Refractive error occurred in $77.9 \%$ of participants (Figure 3 ) and Allergic conjunctivitis in $17.3 \%$. The mean age of occurrence of refractive error was 36.2 years while that for allergic conjunctivitis was 20.5 years (Figure 4). Furthermore the mean age of the glaucoma suspects was 46.6 years, pterygium - 43.3 years, macular degeneration 40.3 years, Cataract- 70 years, and Dry eyes 63.0 years.

\section{N.B}

ANOVA statistics shows that the differences in mean ages by the ophthalmological findings of the participants was statistically significant (ANOVA $=33.35$; -value $=0.00001$ ).

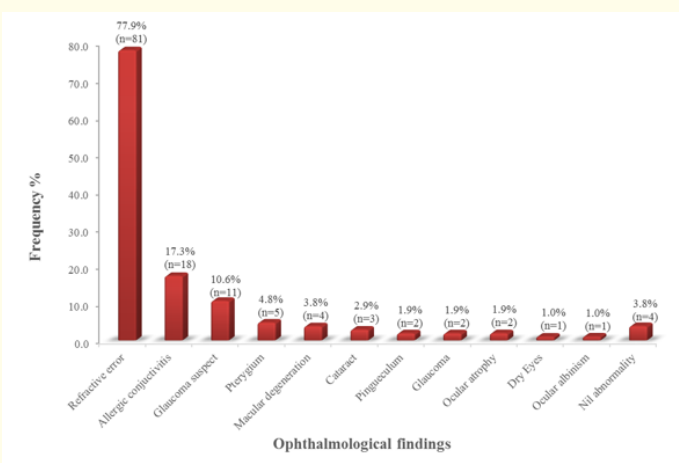

Figure 3: Distribution of ophthalmic findings among participants in the study.

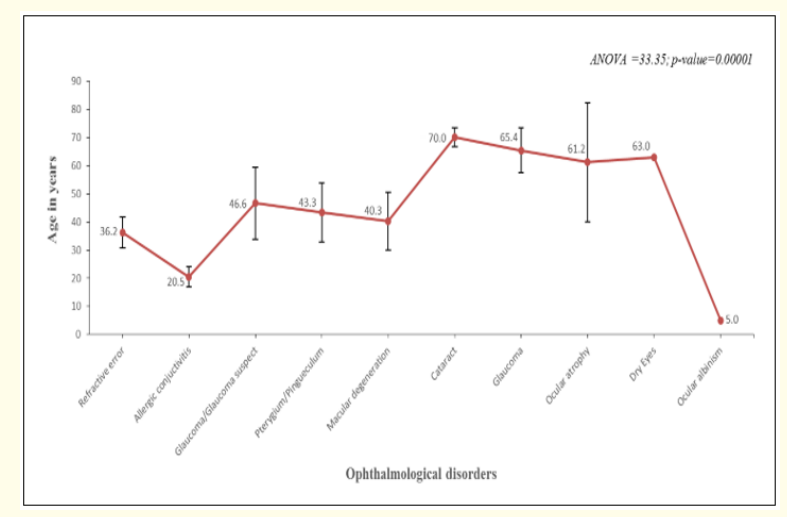

Figure 3: Error bar chart showing mean ages $( \pm 1$ Standard Deviation) of the participants across the ophthalmological disorders.

\section{Discussion}

A sizeable amount of various populations screened have ophthalmic disorders with significant socioeconomic consequences [3]. Osuji in a three day exercise at a rural setting in Enugu state, Nigeria screened 650 people out of whom 466 had eye diseases and the population consisted of $37.3 \%$ male and $62.7 \%$ females (M:F $=1: 2$ ). Our study population was also made up of more females [71.2\%] than males [28.8\%] which is a common trend in many series [4-6]. This may be due to culture, attitude or socioeconomic factors. This is in line with the greater health-seeking behavior of women in many parts of Nigeria primarily because they are economically disadvantaged compared to the men. In contrast studies in Northern Nigeria [4] and India report the reverse [7] probably due to cultural restrictions on women. There is a large body of evidence that women are $40 \%$ more affected by blindness and visual impairment than men [8]. The reason may be that men are more financially able to afford eye care unlike the women and in polygamous settings older wives tend to be neglected in favour of the youngest one. So if their grown children are not available or are unable to take financial responsibility for their health they remain without intervention [9]. Visual impairment in older adults produces difficulty with mobility, challenges for medication management, poor psychological health, overall worse health outcomes, and increased health care spending. Therefore, promoting the visual health of the elderly, especially women is not only a public health concern, but also an economic one. The age group with the largest number of participants in this study was the 41 - 50 years group. 
This agrees with similar studies done at Enugu, Southeastern Nigeria [11], Northern Nigeria [12] and other parts of the country [13-15] From table 1 the visual acuity was greater than $6 / 18$ in the right eyes of $79.8 \%$ and the left eyes of $78.8 \%$ of the participants, so it is not surprising that the 41 - 50 years age group was the largest group, since these are presbyopic people with good distance vision. In Nigeria, its around this age that many patients come out of denial and get reading glasses for the first time. The 31 - 40 years age group also has a large representation because some African patients have early-onset presbyopia which may present even before the age of 35 years and is always of great concern to the patient. Unfortunately according to 2019 estimates, the life expectancy in Nigeria stands at 54.49 years and this may account for the $2.9 \%$ attendance of people over the age of 70 years who in a country like Japan with a life expectancy of 84.55 years would have formed a much larger percentage. Visual impairment is known to increase with age amongst all racial and ethnic groups [10]. There was a statistically significant association between the mean ages of participants and various ophthalmic disorders. The mean age for refractive orders was 20.5years while that for cataract was 70.0years.

The commonest ocular disorder seen was refractive error which presented in $77.9 \%$ of participants, followed by allergic conjunctivitis $\mathbf{1 7 . 3 \%} \mathrm{A}$ few studies done in our region have reported Cataract, uncorrected refractive error [5], Glaucoma, allergic conjunctivitis [13], Refractive error, cataract [16,17], cataract, refractive error [18]. It is noteworthy that refractive error appears in most of the studies as a common cause of ocular morbidity except in the study by Osuji (3) where glaucoma was the commonest ocular disorder followed by cataract and pterygium. Refractive error only made up $3 \%$ of that series probably because his population was largely illiterate. Cataract (2.9\%) did not feature a lot in our study which is an advantage of the semi-urban setting with proximity to professional eye care services while allergic conjunctivitis (77.9\%) featured prominently. Recent studies in the South-south have shown that allergic conjuntivitis plays a major role in ocular mobidity in our area $[19,20]$. This is thought to be linked to environmental pollution mostly from hydrocarbon products.

More than $78 \%$ of the participants had normal vision, $13 \%$ had mild visual impairment similar to the study by Achigbu [5] while 9\% had moderate to severe visual impairment which makes the prevalence of visual impairment in our study $22 \%$. This is in keeping with the global data on visual impairment which is topped by uncorrected refractive errors. Urbanization is associated with a decline in preventable causes of blindness such as cataract and corneal opacity with an increase in causes such as refractive error with some hypertensive and diabetic retinopathy which did not feature in this semi-urban setting. Health challenges seen with urbanization relate to an increase in non- communicable diseases like cardiovascular disease, diabetes, cancers and chronic respiratory disease $[21,22]$. This is seen in our study with a high prevalence of allergic eye diseases.

The implications of our findings on Eye Care Planning and Budgeting are as follows; there is need to set up adequate, costeffective refraction services in each community to address the problem of uncorrected refractive error, tackle the problem of allergic conjunctivitis and other complications of petroleum refining activities in the Niger Delta by sustained advocacy by stake holders assisted by Non-governmental organizations highlighting the potentially catastrophic dangers of inhalation of by-products of hydrocarbon combustion on the respiratory system of the affected population, Finally, preventing blindness from glaucoma can no longer be the sole responsibility of our Ophthalmologists but prominent and well-known members of the society like Politicians, Actors and Sports personalities should join the team by yielding themselves for screening and to publicize intermittent ocular examinations as well as giving financial support so that the people who will not come to the hospital/ other designated screening venues can be reached.

\section{Conclusion}

The prevalence of visual impairment in Rumuapu community is $22 \%$ and the commonest ophthalmic disorder is refractive error, followed by allergic conjunctivitis and glaucoma suspects. The main limitation of this study is the small sample size, so we recommend that a larger scale study be carried out. To include most of the residents of the community. However this pilot study is very important for planning future prevention of blindness programs in this area and other semi-urban locations nationwide.

\section{Conflicts of Interest}

Nil. 


\section{Bibliography}

1. Abraham EG and Megbelayin EO. "Pattern of eye diseases among participants of free eye screening program in Uyo, Akwa Ibom State, Nigeria". International Journal of Community Medicine and Public Health 4.3 (2017): 657-661.

2. The Nigerian National Blindness and Visual impairment survey 2005-2997. Federal Ministry of Health, International centre for Eye Health, Sight Savers International, CBM, Velux Stiftung

3. Osuji SC., et al. "Pattern of eye diseases in a rural community of Enugu, Nigeria". ACTA Scientific Medical Sciences 4.1 (2020): 64-68.

4. Oladigbolu K., et al. "Pattern of eye diseases in a university health service clinic in northern Nigeria". Nigerian Journal of Medicine 21.3 (2013): 334-337.

5. Achigbu EO and Ezeanosike E. "Visual impairment and Blindness in 5 communities in Imo state, South East Nigeria". The Annals of Medical and Health Science Research 7 (2017): 106110.

6. Monsudi KF., et al. "Pattern of eye diseases present at free outreach in rural community in Northwestern Nigeria”. Sudan Medical Monitor 10 (2015): 113-116.

7. Murphy GVS and Sanjeev KG, "Current status of cataract blindness and Vision 2020: The Right to Sight initiative in India". Indian Journal of Ophthalmology 56.6 (2009): 489-494.

8. Courtright $\mathrm{P}$ and Lewallen S. "Why are we addressing gender issues in vision loss?". Community Eye Health 22.70 (2008): 17-19.

9. Lewallen S., et al. "Cataract surgical coverage remains lower in females". British Journal of Ophthalmology 93 (2009): 295298.

10. Umfress AC and Brantley MA. "Eye care disparities and Health related consequences in Elderly patients with age-related eye disease". Seminars in Ophthalmology 31.4 (2016): 432-438.

11. Kyari F., et al. "Prevalence of Blindness and visual impairment in Nigeria. The National Blindness and Visual Impairment Survey". Investigative Ophthalmology and Visual Science 50 (2009): 2033-2039.

12. Guo C. "Prevalence, causes and social factors of visual impairment among Chineese adults: Based on a national survey". International Journal of Environmental Research and Public Health 14 (2017): 1034.
13. Wokoma FS and Ichenwo T. "Pattern of eye disorders in Ogbodo: A rural community in Rivers State". The Nigerian Health Journal 11 (2011): 14-18.

14. Isawumi MA., et al. "Blindness and visual impairment among adults in a tertiary eye clinic in Osogbo SW Nigeria". Annals of Medical and Health Science Research 4 (2014): 594-597.

15. Budenz DL., et al. "Blindness and visual impairment in an urbanWest African population: The Tema eye survey". Ophthalmology 119 (2012): 1744-1753.

16. Agrawal D., et al. "Ocular morbidity pattern of an urban population of meerut". Indian Journal of Preventive and Social Medicine 42 (2011): 74-78.

17. Ukponmwan CE. "Pattern of ocular morbidity in Nigeria". Asian Pacific Journal of Tropical Disease 3 (2013): 164-166.

18. Mehari ZA. "A study of ocular morbidity of patients attending ophthalmic outreach services in rural Ethiopia". International Journal of Medical Sciences 3 (2013): 450-454.

19. Awoyesuku EA., et al. "Distribution of Ocular Disorders in Communities Affected by crude oil- spillage in Rivers State". Ophthalmology Research: An International Journal 11.3 (2019): 1-5. https://dx.doi.org/10.9734/OR/2019/v11i330126

20. Chukwuka IO., et al. "Ocular morbidity pattern in Abonnema, Akoku-Toru local government area of Rivers State". Annals of Biomedical Sciences 16.2 (2017): 133-139.

21. Global visual impairment. https://www.iapb.org/ vision.2020/who.facts

22. Urbanization and health. https://www.who.int/bulletin/volumes/88/4/10-010410/en/

\section{Assets from publication with us}

- Prompt Acknowledgement after receiving the article

- Thorough Double blinded peer review

- Rapid Publication

- Issue of Publication Certificate

- High visibility of your Published work

Website: www.actascientific.com/

Submit Article: www.actascientific.com/submission.php

Email us: editor@actascientific.com

Contact us: +919182824667 